\title{
TEKNIK PENGOPERASIAN JARING CUMI-CUMI DENGAN MENGGUNAKAN ALAT BANTU CAHAYA
}

\author{
Agus Salim \\ Teknisi Litkayasa pada Balai Riset Perikanan Laut, Muara Baru-Jakarta \\ Teregistrasi I tanggal: 9 Juli 2007; Diterima setelah perbaikan tanggal: 23 Oktober 2007; \\ Disetujui terbit tanggal: 2 Nopember 2007
}

\section{PENDAHULUAN}

Pertumbuhan kapal jaring cumi-cumi saat ini berlangsung sangat pesat dengan ukuran yang bervariasi. Armada jaring cumi-cumi yang berbasis di Juwana pada umumnya berukuran $<30 \mathrm{GT}$, sementara di Muara Angke dan Muara Baru pada umumnya berukuran >30 GT. Kapal jaring cumi-cumi pada umumnya menggunakan mesin penggerak dengan kekuatan 120 PK (4-8 silinder). Daya lampu yang digunakan berkisar 19.000-50.000 watt. Sumber tenaga lampu menggunakan dinamo yang mampu mensuplai daya $25.000-80.000$ watt.

Berdasarkan pada hasil pengukuran (LOA) pada 15 kapal jaring cumi-cumi yang berbasis di Juwana diperoleh kisaran panjang $(P)$ 14,30-19,10 m, Lebar (L) 4,35-6,60 m dan dalam (D) 2,0-2,5 m. Jaring cumicumi menggunakan alat bantu cahaya lampu untuk memikat ikan, sehingga dikelompokkan dalam light fishing. Prinsip penangkapan ikan dengan menggunakan alat tersebut pada dasarnya memanfaatkan tingkah laku ikan. Menurut Ayodhyoa (1981), peristiwa berkumpul ikan di bawah sumber cahaya disebabkan ikan mempunyai sifat fototaksis positif atau ikan yang secara tidak langsung tidak tertarik dengan cahaya melainkan karena ada makanan yang dapat dimangsa.

Kapal jaring cumi-cumi yang berbasis di Juwana berfungsi ganda. Artinya, pada musim cumi-cumi dioperasikan untuk menangkap cumi-cumi sebagai sasaran tangkapan, sedangkan pada waktu tidak musim cumi-cumi beroperasi untuk menangkap ikan tenggiri. Alat yang digunakan untuk menangkap ikan tenggiri adalah pancing tangan (hand line), sedangkan jaring cumi-cumi dioperasikan untuk menangkap ikan umpan.

Kedalaman penetrasi cahaya dalam laut tergantung oleh beberapa faktor, antara lain absorbsi cahaya oleh fartikel-fartikel air, panjang gelombang cahaya, kecerahan air, pemantulan cahaya oleh permukaan laut, musim dan lintasan peografis (Nybaken, 1988).

\section{BAHAN DAN METODE}

Penelitian dilakukan di perairan utara Jawa, Juwana, Jawa Tengah dengan menggunakan unit penangkapan jaring cumi-cumi. Operasi penangkapan dilakukan pada posisi sekitar $06^{\circ} 44^{\prime} 005^{\prime \prime}$ LS dan 109¹9'285" BT. Pengukuran kuat cahaya di atas kapal jaring cumi-cumi dengan meggunakan quantum meter LI-192 SA dengan satuan $\mu \mathrm{mol} \mathrm{s}^{-1} \mathrm{~m}^{-2}$. Pengukuran dilakukan pada 3 titik sisi kapal yang dianggap ada perbedaan dari sebaran kuat cahaya yang digunakan yaitu pengukuran pada sisi tengahtengah kapal, pengukuran antara ujung (haluan) dan tengah-tengah kapal, dan pengukuran pada depan (haluan) kapal.

Lampu yang digunakan pada kapal jaring cumicumi terdiri atas lampu halogen 3.000 watt, galaxy 800 watt, mercury 1.200 watt, dan bohlam biasa dengan kekuatan 3.000 watt. Lampu dipasang menyebar pada kedua sisi kapal (kanan kiri ), dengan total daya 19.000 watt.

Jaring cumi-cumi ini dioperasikan dengan kapal berukuran $15 \mathrm{GT}$ (panjang $16 \mathrm{~m}$, lebar $4,5 \mathrm{~m}$, dan dalam $2 \mathrm{~m}$ ) dengan mesin penggerak PS 120 ditambah mesin pembantu diesel 20 PK. Satu sisi kapal dilengkapi 2 buah bum dari bambu yang berfungsi untuk merentangkan jaring keluar kapal, masing-masing bum panjang $10 \mathrm{~m}$. Pada bum dilengkapi tali dan pen (besi) untuk mengikat tali pada jaring dan tali yang ada di bum dengan cara dijepit dengan pen. Jaring cumi-cumi beroperasi dalam 1 trip pada umumnya selama 15-20 hari (selama gelap bulan), dengan anak buah kapal berjumlah 7-9 orang.

\section{HASIL DAN BAHASAN}

\section{Spesifikasi Alat Tangkap}

Alat tangkap jaring cumi-cumi secara umum menyerupai alat tangkap jala tebar, yaitu mempunyai spesifikasi sebagai berikut, panjang jaring dari pangkal sampai kantong $12 \mathrm{~m}$, bahan terbuat dari PE dan PA multifilament $(\mathrm{d} / 6-\mathrm{d} / 15)$, lebar mata jaring (mesh size) 
terdiri atas 3/4 inci pada kantong dan 1 inci selain bagian kantong. Pada pangkal jaring dipasang serampat yang terbuat dari bahan webbing PE 1" $\mathrm{d} /$ 15 dengan tinggi 5 mata dan diberi tali ris $P E \varnothing 8$ $\mathrm{mm}$, panjang $32 \mathrm{~m}$. Pada bagian bawah (pangkal) jaring dilengkapi dengan pemberat timah $150 \mathrm{~kg}$ dan ring 80 buah $(25 \mathrm{~kg})$. Ring berfungsi sebagai kolongan (cincin) tali kolor PE $\varnothing 18 \mathrm{~mm}$ sepanjang $40 \mathrm{~m}$. Spesifikasi alat tangkap jaring cumi-cumi disajikan pada Gambar 1.

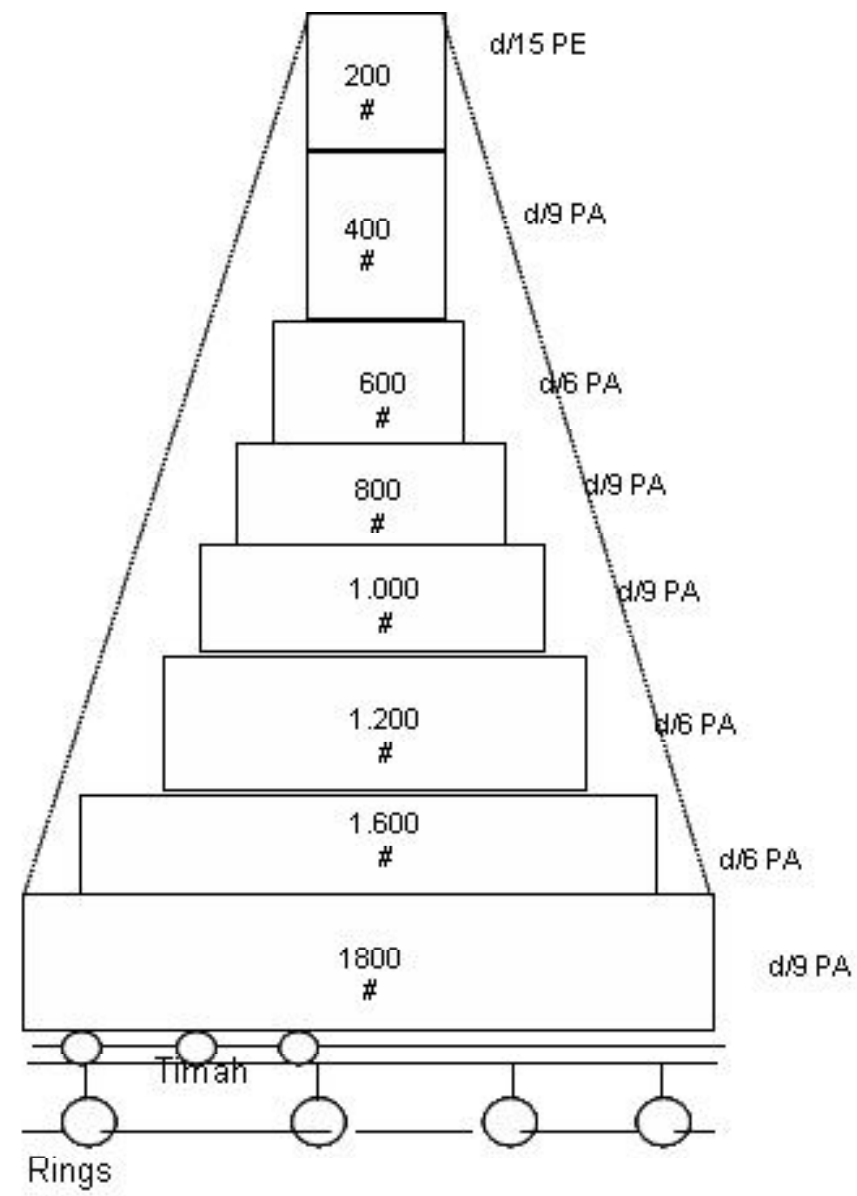

Gambar 1. Spesifikasi jaring cumi-cumi yang berbasis di Juwana.

\section{Pengoperasian Jaring Cumi-cumi}

Jumlah tawur jaring cumi-cumi dalam 1 malam dapat berulang-ulang, mencapai 6-8 kali tawur, tergantung ada ikan yang berkumpul di bawah cahaya lampu. Adapun cara pengoperasian jaring cumi-cumi sebagi berikut:

1. Setelah ikan banyak berkumpul di bawah cahaya lampu, jaring cumi-cumi siap untuk dioperasikan, dengan cara jaring dibentangkan sehingga membentuk segi empat sama sisi, kedua sisi kanan dan kiri jaring dikaitkan pada tali yang ada di bum, lalu dijepit dengan sebuah pen (besi) agar mudah lepas saat jaring di jatuhkan.

2. Posisi jaring dalam keadaan rentang, 1 sisi jaring ada pinggir kapal, dan 3 sisi ada di luar kapal atau di atas permukaan air.

3. Agar ikan lebih terkonsentrasi, lampu secara bertahap dipadamkan sampai hanya 1 lampu (lampu tawur) yang menyala dan telah diberi kap (tutup) berwarna merah (halogen 400 watt).
4. Setelah diperkirakan cumi-cumi atau ikan terkonsentrasi di bawah sinar lampu (halogen 400 watt), jaring dijatuhkan (dilepas) secara serentak, dengan cara menarik tali pen agar jaring terlepas dari tali bum, tali kolor diulur sampai kedalaman yang dikehedaki.

5. Tali kolor kemudian ditarik dengan bantuan gardan, sampai bagian pangkal jaring mengerut (menutup) sehingga ikan dapat terkurung di dalam jaring.

6. Lampu dinyalakan kembali, selanjutnya jaring diangkat ke atas kapal dan ikan hasil tangkapan diambil melalui ujung jaring (kantong).

\section{Pengaruh Cahaya}

Berdasarkan pada hasil pengukuran secara vertikal kuat cahaya kapal jaring cumi-cumi pada 3 titik (tengah, antara tengah, dan ujung). Secara umum, menunjukkan pola sebaran yang hampir sama. 
Gambar 2, memperlihatkan bahwa sebaran vertikal cahaya untuk tengah kapal secara efektif terdapat kuat cahaya pada kedalaman $11 \mathrm{~mm}$ dengan nilai kuat cahaya $0,014 \mu \mathrm{mol} \mathrm{s} \mathrm{m}^{-2}$ dan pada jarak $1 \mathrm{~m}$ di bawah permukaan air diperoleh nilai kuat cahaya 0,04 $\mu \mathrm{mol} \mathrm{s}{ }^{-1} \mathrm{~m}^{-2}$. Sebaran vertikal cahaya antara tengah dan ujung kapal secara efektif terdapat kuat cahaya sampai kedalaman $8 \mathrm{~m}$ dengan nilai kuat cahaya 0,08 $\mu \mathrm{mol} \mathrm{s} \mathrm{s}^{-1} \mathrm{~m}^{-2}$, sedangkan sebaran vertikal cahaya ujung kapal secara efektif terdapat kuat cahaya sampai kedalaman $6 \mathrm{~m}$ dengan nilai kuat cahaya 0,01 $\mu \mathrm{mol}$ $\mathrm{s}^{-1} \mathrm{~m}^{-2}$ dan pada jarak $1 \mathrm{~m}$ di bawah permukaan air diperoleh nilai kuat cahaya $0,04 \mu \mathrm{mol} \mathrm{s}^{-1} \mathrm{~m}^{-2}$.

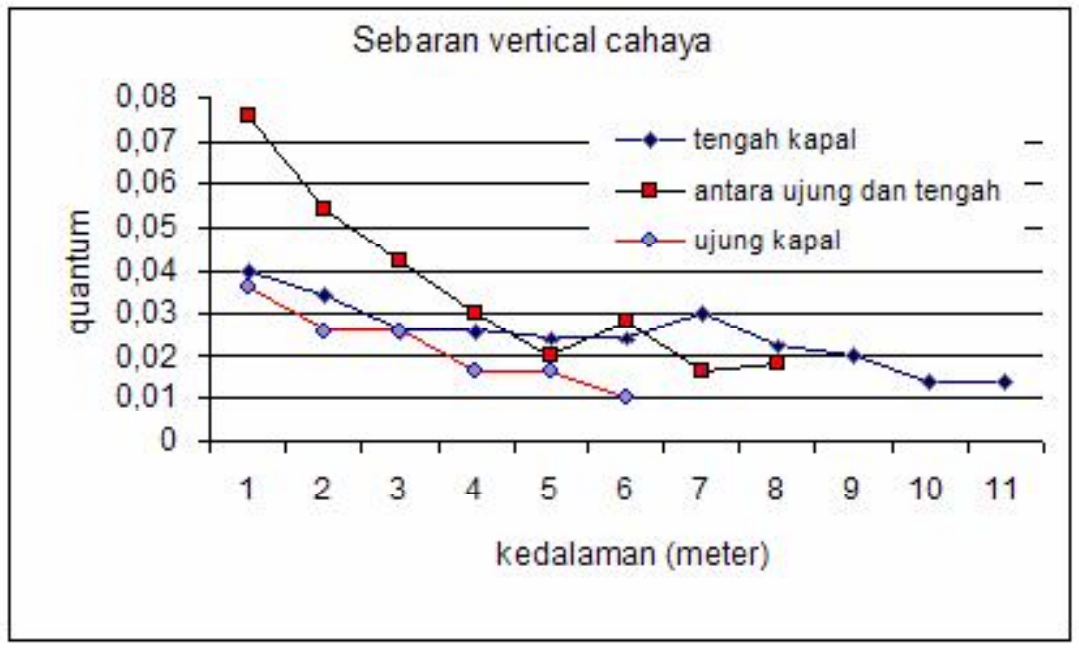

Gambar 2. Sebaran cahaya secara vertikal.

\section{Hasil Tangkapan}

Nelayan jaring cumi-cumi Juwana beroperasi di perairan utara Jawa pada posisi $03-04^{\circ} \mathrm{LS}$ dan 110 $113^{\circ}$ BT atau utara Pulau Bawean (Gambar 3). Pada saat musim cumi-cumi, jaring cumi-cumi dioperasikan untuk menangkap cumi-cumi sebagai sasaran tangkapan dan beroperasi di sekitar posisi $110^{\circ} \mathrm{BT}$. Pada bulan tidak musim cumi-cumi jaring cumi-cumi hanya untuk menangkap umpan pancing tenggiri dan beroperasi pada posisi $111-113^{\circ}$ BT. Berdasarkan pada data yang tersedia di tempat pendaratan ikan
Juwana, rataan produktivitas jaring cumi-cumi tertinggi ditemukan pada bulan Nopember (2.288 kg per kapal per bulan). Sementara itu, produksi terendah terjadi pada bulan Juni (1.118 $\mathrm{kg}$ per kapal per bulan). Keadaan ini menunjukkan ada kesamaan dengan yang terjadi di Selat Lombok bahwa musim cumi-cumi datang beriringan dengan datang musim penghujan, yaitu pada bulan Oktober-Nopember. Terjadi musim tersebut karena ada penambahan zat hara (nutrien) yang terbawa arus musim dari arah barat dan pengaruh ada umbalan air yang terjadi di bagian selatan Jawa dan Sumbawa (Soselisa et al., 1986).

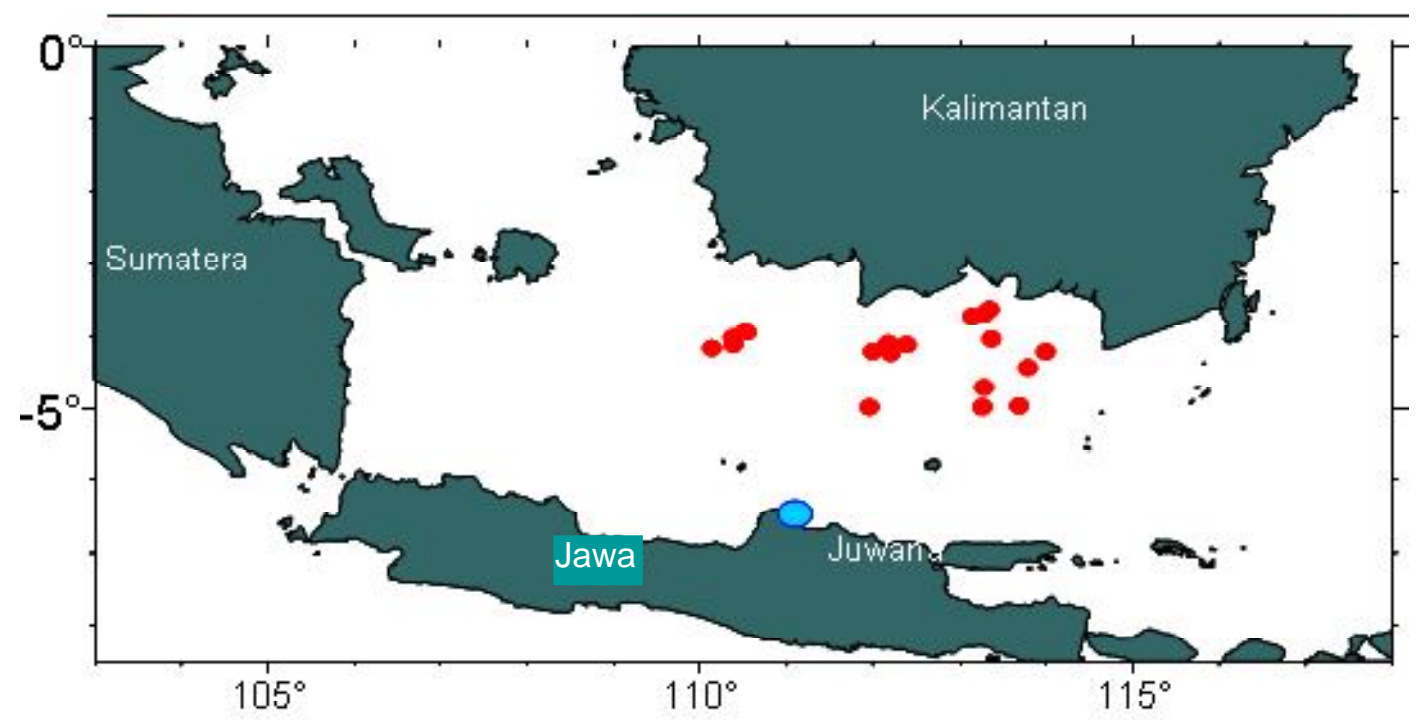

Gambar 3. Daerah penangkapan jaring cumi-cumi yang berbasis di Juwana. 
Pengopersian jaring cumi-cumi dengan menggunakan alat bantu cahaya dilakukan pada periode tahun 2005. Penangkapan pada umumnya dilakukan pada malam hari selama 1 gelapan bulan (15-20 hari). Hasil tangkapan ini sangat sedikit bila dibanding dengan hasil tangkapan trip sebelum. Hal ini disebabkan karena cuaca yang buruk sehingga pengoperasian alat tidak berjalan dengan baik. Hasil tangkapan jaring cumi-cumi didominansi oleh ikan siro (Amblygaster sirm) $939,5 \mathrm{~kg}$, talang-talang (Scombberoides lysan) $71,5 \mathrm{~kg}$, kacangan $52 \mathrm{~kg}$, dan cumi-cumi $51,2 \mathrm{~kg}$. Hasil tangkapan lain adalah jenis ikan swanggi, bentong, tenggiri, dan sunglir (Tabel 1, Gambar 4).

Tabel 1. Hasil tangkapan jaring cumi-cumi (kg) per trip

\begin{tabular}{|c|c|c|c|c|c|c|c|c|}
\hline \multirow{2}{*}{$\begin{array}{c}\text { No. } \\
\text { Tawur }\end{array}$} & \multicolumn{8}{|c|}{ Hasil tangkapan (kg) } \\
\hline & Siro & Talang-talang & Cumi-cumi & Swanggi & Bentong & Tenggiri & Kacangan & Sunglir \\
\hline 1 & 50 & 0,5 & 1 & 0,5 & & & & \\
\hline 2 & & 1 & 0,7 & & 1 & & & \\
\hline 3 & 4,5 & 4 & 8 & 0 & 1,5 & 1 & & \\
\hline 4 & 1 & 6 & & & & & & \\
\hline 5 & 80 & & & & & & & \\
\hline 6 & 4 & & 2,5 & & & & & \\
\hline 7 & 40 & 10 & & & & & & \\
\hline 8 & 90 & 30 & 1,4 & & & & 50 & \\
\hline 9 & 20 & 20 & 0,4 & 2,5 & & & 2 & \\
\hline 10 & 250 & & & 2 & & & & \\
\hline 11 & 400 & & & & & & & \\
\hline 12 & & & 0,2 & & & & & 1 \\
\hline 13 & & & 22 & & & & & \\
\hline 14 & & & 5 & & 0,4 & & & \\
\hline 15 & & & 10 & & & & & \\
\hline Total & 939,5 & 71,5 & 51,2 & 5 & 2,9 & 1 & 52 & 1 \\
\hline
\end{tabular}

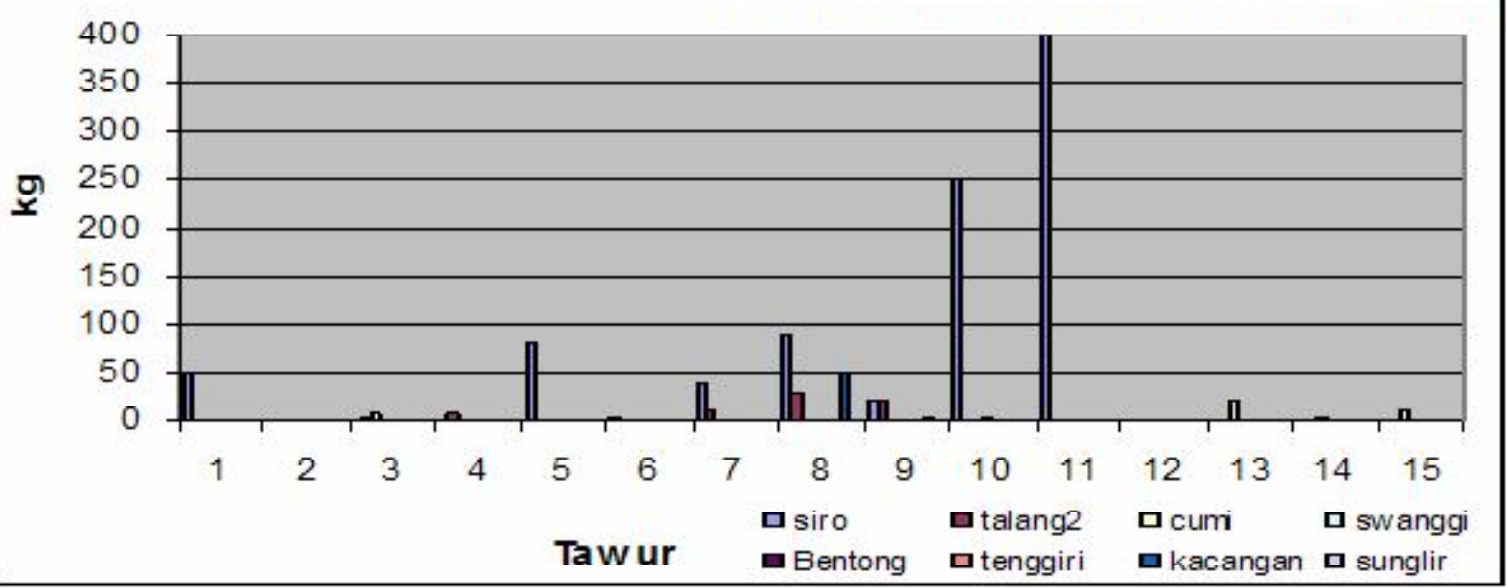

Gambar 4. Total hasil tangkapan jaring cumi-cumi.

\section{Aspek Biologi}

Pengambilan contoh dilakukan terhadap 3 jenis ikan atau cumi-cumi, yaitu cumi-cumi jarum (Loligo urtteuthisbartschi) 177 ekor, cumi-cumi tarusan (Loligo duvaucelli) 71 ekor, dan ikan siro (Amblygaster sirm). Hasil pengukuran terhadap panjang mantel cumi-cumi jarum diperoleh rata-rata 10,65 cm. Gambar 5 memperlihatkan bahwa frekuensi panjang mantel didominansi pada kisaran $11-15 \mathrm{~cm}$ dan terendah pada kisaran $1-5 \mathrm{~cm}$. Hasil pengukuran terhadap panjang mantel cumi-cumi tarusan diperoleh kisaran rata-rata $7,26 \mathrm{~cm}$. Gambar 6, memperlihatkan bahwa frekuensi panjang mantel didominansi pada kisaran $6-10 \mathrm{~cm}$ dan terendah pada kisaran 11-15 cm. Hasil pengukuran terhadap panjang cagak (FL) ikan siro diperoleh rata-rata $17,44 \mathrm{~cm}$. Gambar 7 memperlihatkan bahwa frekuensi panjang cagak didominansi pada kisaran $17-17,5 \mathrm{~cm}$ dan terendah pada kisaran $19-19,5 \mathrm{~cm}$. 


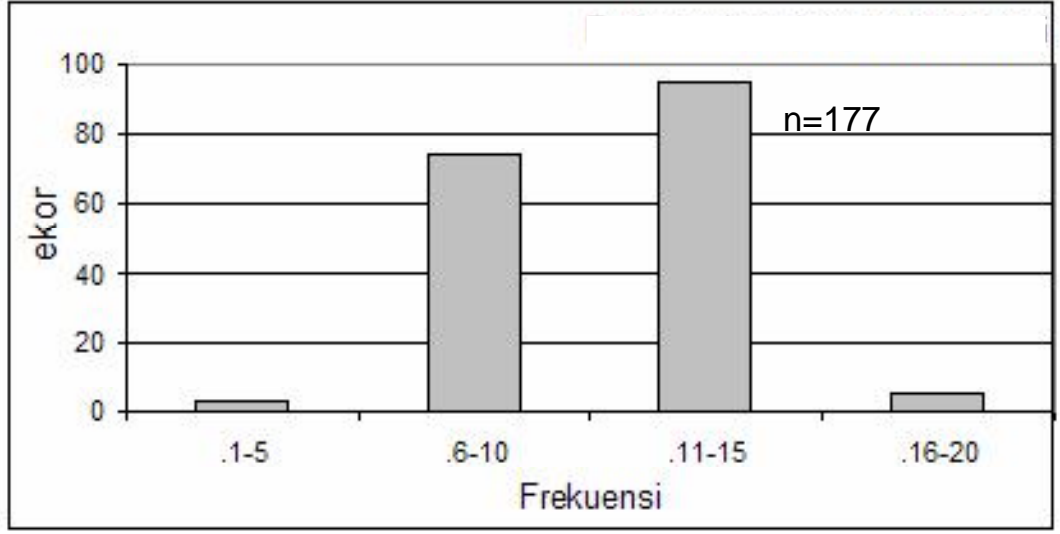

Gambar 5. Sebaran frekuensi panjang mantel cumi-cumi jarum (L. urtteuthisbartschi).

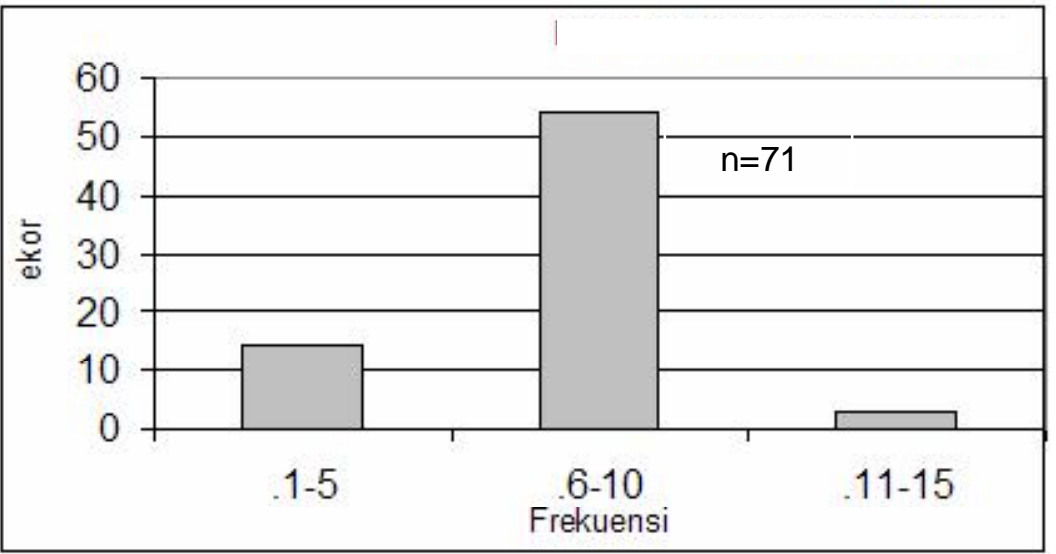

Gambar 6. Sebaran frekuensi panjang mantel cumi-cumi tarusan (L. duvaucelli).

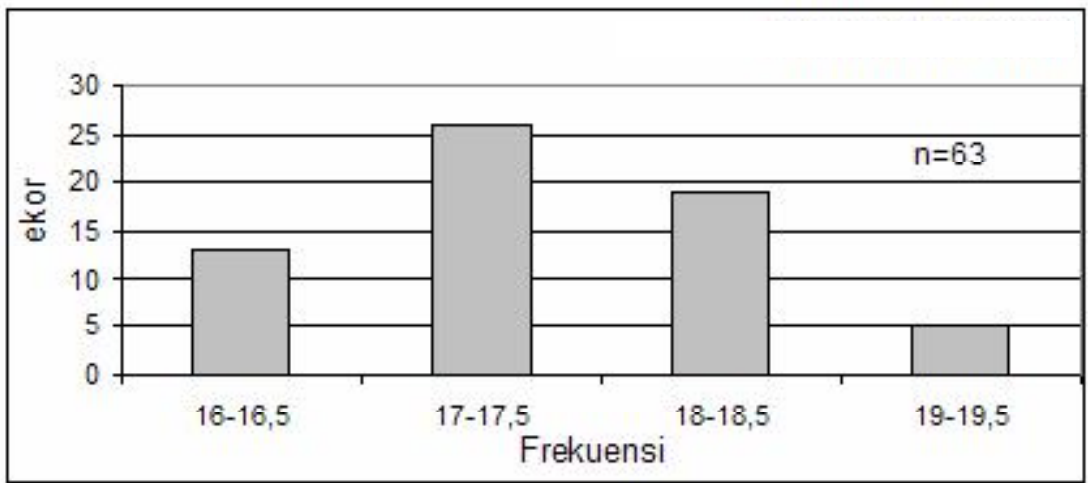

Gambar 7. Sebaran frekuensi FL ikan siro (A. sirm).

\section{KESIMPULAN}

1. Jaring cumi-cumi tergolong dalam alat tangkap Ligh fishing karena menggunakan cahaya lampu untuk menarik gerombolan ikan.

2. Nelayan jaring cumi-cumi Juwana beroperasi di perairan utara Jawa pada posisi $03-04^{\circ}$ LS dan $110-113^{\circ} \mathrm{BT}$ atau utara Pulau Bawean.

3. Hasil tangkapan jaring cumi-cumi didominansi oleh ikan siro $939,5 \mathrm{~kg}$, talang-talang $71,5 \mathrm{~kg}$, dan cumicumi $51,2 \mathrm{~kg}$.

\section{DAFTAR PUSTAKA}

Ayodhyoa. 1981. Metode Penangkapan Ikan. Yayasan Dewi Sri. Bogor.

Soselisa, Y., S. Marjuki, \& W. Subani. 1986. Jurnal Penelitian. No.34. Balai Riset Perikanan Laut. Jakarta.

Nybaken, J. W. 1988. Biologi laut. Gramedia Pustaka Utama. Jakarta. 